\title{
POLÍTICA, ESTADO E DEMOCRACIA EM MAQUIAVEL, WEBER E ELLEN WOOD
}

\author{
POLITICS, STATE AND DEMOCRACY IN MAQUIAVEL, WEBER AND ELLEN \\ WOOD
}

Weslei Trevizan Amâncio ${ }^{1}$

\begin{abstract}
RESUMO: O presente artigo tem como objetivo realizar uma abordagem introdutória ao pensamento da política, Estado e democracia presentes em Nicolau Maquiavel, Max Weber e Ellen Wood apresentados, respectivamente, nas obras "O Príncipe", "A Política como Vocação" e "Democracia Contra Capitalismo: a renovação do materialismo histórico". Para tanto, elencamos algumas das principais questões que tangenciam as reflexões e estudos dos autores sobre os temas propostos e que, ao mesmo tempo, orientaram este trabalho. A grandeza das definições produzidas pelos autores, ainda que obviamente não deem conta de toda a complexidade que abrangem o desenvolvimento histórico e social, é que muito de sua essência, com maior ou menor intensidade, estão presentes e nos ajudam a compreender fatos e fenômenos que hoje se encontram envoltos e acometem a política, o Estado e a democracia, possibilitando entender de forma mais clara as intenções e motivações que estão por trás de muitas ações, bem como mensurar pontos positivos e negativos dos impactos esperados e mesmo desdobramentos e consequências advindas.
\end{abstract}

Palavras-chave: Política; Estado; Democracia.

\begin{abstract}
The present article aims at an introductory approach to the thinking of politics, state and democracy present in Nicholas Machiavelli, Max Weber and Ellen Wood presented respectively in the works "The Prince", "Politics as a Vocation" and "Democracy Against Capitalism: the renewal of historical materialism ". To do so, we list some of the main issues that touch upon the reflections and studies of the authors on the proposed themes and, at the same time, guided this work. The greatness of the definitions produced by the authors, although they obviously do not account for all the complexity that encompasses historical and social development, is that much of their essence, to a greater or lesser extent, are present and help us to understand facts and phenomena that today they are involved and attack politics, the state and democracy, making it possible to understand more clearly the intentions and motivations that are behind many actions, as well as measuring positive and negative points of the expected impacts and even consequences and consequences.
\end{abstract}

Keywords: Politics; State; Democracy.

\footnotetext{
${ }^{1}$ Mestrando no Programa de Pós-Graduação em Ciências Sociais da UNIOESTE - Campus Toledo. E-mail: wesleitamancio@gmail.com
} 


\section{INTRODUÇÃO}

A proposição do presente artigo está relacionada às leituras, anotações, análises, debates e provocações desenvolvidas e compartilhadas na disciplina de Teoria Política, do Programa de Mestrado em Ciências Sociais da UNIOESTE - Campus Toledo.

Diante disso, o objetivo estruturado é realizar uma abordagem introdutória ao pensamento da política, Estado e democracia presentes em Nicolau Maquiavel, Max Weber e Ellen Wood apresentados, respectivamente, nas obras "O Príncipe", "A Política como Vocação" e "Democracia Contra Capitalismo: a renovação do materialismo histórico".

Neste processo, não se pode perder de vista que as trajetórias de cada um dos autores, bem como seus objetos e objetivos de estudo, estão permeadas por distintos significados, expressões, particularidades, interesses, diante das posições de classes ocupadas, do período histórico e experiências vividas.

Para tanto, a fim de consolidar as proposições apresentadas, elencamos algumas das principais questões que tangenciam as reflexões e estudos dos autores sobre os temas propostos - apresentados de forma sucinta, porém, com fecundas contribuições - e que, ao mesmo tempo, orientaram este trabalho.

\section{MAQUIAVEL E A POLÍTICA COMO AÇÃo}

Em “O Príncipe”, Maquiavel (1996), pela primeira vez entre os teóricos, produz uma análise da política separada de valores ético e moral. A política deve ser vista como possuidora de leis próprias.

Entre os desdobramentos do ensinamento contido na obra, depreende-se que na política os fatos devem ser trabalhados como eles são ao invés de como deveriam ser.

Independentemente do que se queira ser ou fazer, a compreensão e saber utilizar os meios disponíveis, métodos e procedimentos, para ser feito o que é necessário é de fundamental importância para a sustentação política. Fazer política é atuar no mundo de forma prática (MAQUIAVEL, 1996).

\footnotetext{
“A missão prática não só motiva Maquiavel como ilumina todo o livro. É a partir dela que se põe as questões técnicas e teóricas enfrentadas no texto: as formas de acesso ao poder, os meios de ação e sua hierarquia, as qualidades necessárias ao governante, as exigências próprias da ação política, as considerações sobre a natureza humana e as possibilidades de ação, delimitadas pelo contraste da virtù e da Fortuna." (KRITSCH, 2001, p.181).
} 
Nesta esteira, de acordo com Kritsch (2001, p. 189), à política deve comportar dois fins, que são fundamentais. "O fim mínimo da política, para Maquiavel, pode ser reduzido a dois aspectos: a manutenção da ordem pública nas relações internas; e a defesa da integridade da pátria nas relações externas".

A história é percebida como uma realização alternada de movimentos permeados pelo caos e ordem, sucessivamente. Desta forma, a história é entendida como algo não linear, tão pouco única e universal.

A força da ordem e desordem histórica tem dois elementos fundamentais. O primeiro, os que se encontram em funções e locais privilegiados querem manter as condições, para tanto, não sessam de organizar a exploração e opressão sobre os que se encontram nas posições de baixo. O segundo, como decorrência do primeiro, os que estão embaixo lutam para cessar as condições de exploração e opressão que abatem sobre si.

Quanto ao Estado - Maquiavel também é o primeiro autor a considerar esse fato - é visto como o detentor do poder central e, por consequência, instrumento de atuação sobre esses movimentos.

\footnotetext{
"Constituir o Estado envolve ordenar a vida do povo e das pessoas ou grupos, organizar interesses potencialmente conflitantes. Isto pode dar-se tanto pelo abafamento dos conflitos quanto por sua canalização ou regulamentação. Fazê-lo requer um poder baseado na força, capaz de gerar instituições (exército, leis, normas fundamentais, religião). $\mathrm{Na}$ fundação do poder consolida-se, num primeiro momento, o comando; num segundo momento, dá-se forma (principado ou república) ao governo, pensando como instituição que regulamenta a força e atende a demandas." (KRITSCH, 2001, p.189).
}

Cabe ao Príncipe lidar da melhor forma possível com a realização dos fins mínimos esperados da política e a alternância dos momentos históricos vividos. A função da política, neste contexto, é construir o novo dentro das condições dadas (CARLI, 2015).

Ao Príncipe também é atribuída uma ação central, sendo concebida como uma figura destinada a unificar as nações. Esta concepção atribuída ao Príncipe deve ser vista à luz do momento histórico vivido por Maquiavel e o claro objetivo que tem em promover a unificação da Itália para fazer frente a outras nações que vinham se consolidando e se apresentavam como uma ameaça, como a Alemanha, França e Espanha (CARLI, 2015).

Em um estudo, sobre a obra em comento, Kritsch (2001, p. 181) apresenta o seguinte entendimento: 


\begin{abstract}
"Em Maquiavel é muito claro que a política e a reflexão que sobre ela se faz constituem aspectos indissociáveis. O Príncipe é a prova mais evidente disso. Embora tenha sido uma obra lida por muitos ao longo dos séculos como um "manual" ou receituário para o governante que desejasse se tornar um príncipe virtuoso em qualquer tempo e lugar - o que evidencia seu caráter de tratado teórico -, Maquiavel não escondeu de seus leitores que o livro tinha um sentido prático e imediato, explicitamente declarado no último capítulo. Nele se lê uma exortação em favor da "unificação da Itália" e da expulsão dos estrangeiros. A ideia de um projeto nacional, missão que Maquiavel atribuía àquele que assumisse a tarefa de unificar, libertar e pacificar a Itália, expressa-se no poema Petrarca. É essa mensagem final, portanto, que deve incentivar a ação e permanecer gravada nelli italici cor e, de modo muito especial, no coração de um príncipe disposto a redimir a Itália "espoliada, lacerada, invadida" - das "crueldades e insolência bárbaras".
\end{abstract}

Mas, afinal quem é ou pode vir a ser o príncipe? Para Maquiavel (1996) ao príncipe requer a dotação de algumas qualidades e capacidades. Qualidade de realizar a leitura dos movimentos já descritos e, sobretudo, a capacidade de fazer o seu destino e, neste processo, a capacidade de fazer o que deve ser feito. Os termos referenciados pelo teórico para essas qualidades e capacidades é possuir Fortuna e/ou a virtù.

A Fortuna pode ser entendida como o conjunto de determinadas circunstâncias que recobrem podendo determinar ações, exigindo, em contrapartida, apenas um mínimo esforço de uma resposta eficaz. Ela se sobrepõe nos momentos e espaços onde não encontramos uma virtù devidamente ordenada, oferecendo resistência. Todavia, um príncipe que se apoie exclusivamente na Fortuna tem a sustentação do seu poder a mercê de circunstâncias favoráveis, podendo ter seu poder arruinado com a mudança da conjuntura (KRITSCH, 2001).

Assim, a virtù é a qualidade capaz de dominar a Fortuna. A virtù, na interpretação de Kritsch (2001, p. 188) é

“[...] a capacidade de agir em face da Fortuna, aproveitando uma circunstância favorável, resistir aos fatos e, se possível, antecipar-se a eles, conquistando a honra para si e segurança para o Estado. Em última instância, virtù é a capacidade de produzir história. Esta é a capacidade que cabe ao príncipe."

De certa forma, a qualidade e a durabilidade de um governo estão vinculadas com a virtù e a Fortuna do príncipe, de modo que a elas ligam a ordenação política e relações político-institucional que permite a manutenção e desenvolvimento da sociedade.

\title{
ESTADO E O MONOPÓLIO DA VIOLÊNCIA EM MAX WEBER
}


“A Política como Vocação" é a materialização de uma conferência realizada por Max Weber em 1918. Nela a política é trabalhada de forma separada, vista sob normas específicas - com regras e ética que lhe são próprias - e atrelada a uma vertente estatal.

Neste sentido, a política, para as finalidades das reflexões empreendidas por Weber, deve ser compreendida como "a direção do agrupamento político hoje denominado "Estado" ou a influência que se exerce em tal sentido" (WEBER, 2012, p. 55).

Quanto a noção de estado, Weber concorda com Trotsky de que todo o Estado se funda na força. Em decorrência, ao Estado é dado a definição de "comunidade humana que, dentro dos limites de determinado território - a noção de território corresponde a um dos elementos essenciais do Estado - reivindica o monopólio do uso legítimo da violência física" (WEBER, 2012, p. 56).

Por conseguinte, cabe o entendimento de política como "o conjunto de esforços feitos com vistas a participar do poder ou influenciar a divisão do poder, seja entre Estados, seja no interior de um único Estado" (WEBER, 2012, p. 56).

De toda forma, de acordo com Weber (2012), assim como os todos os diferentes agrupamentos político existente anterior ao Estado, ele também deve ser visto como a consistência de uma relação de dominação do homem sobre o homem, que é reconhecida e amparada no entendimento dele como instrumento para o exercício da violência legítima da força. Esse Estado, portanto, só existe com o reconhecimento e submissão dos homens dominados à autoridade dos que se reivindicam e exercem a dominação.

Neste processo, o homem obedece por dois fatores: por medo ou esperança. Diante desses entendimentos, Weber (2012) estrutura três razões justificadoras do exercício da dominação, que tem, por consequência, três fundamentos de legitimidade: a tradicional; a carismática; e a legal.

Sobre esse quadro de definições weberianas, Godoy (2012, p. 1-2) sintetiza:

\footnotetext{
“Assentado que no Estado tem-se a dominação do indivíduo sobre o indivíduo, necessário que se averigue sobre quais condições se desenvolveria esse domínio. Para Weber, há sobre nós uma autoridade recorrente do passado, que denominou de "poder tradicional". Haveria uma segunda forma, marcada por dons pessoais e extraordinário de alguns líderes, que se denominou de "poder carismático". Por fim, uma forma de dominação que explicita uma competência positiva, de base racional, que Weber teria chamado de "dominação pela legalidade".
} 
Analisando as definições de dominação, pode-se depreender que a dominação tradicional se baseia na crença do "sempre foi assim", vinculado a previsibilidade e segurança requeridas nas sociedades camponesas. A dominação carismática também se funda em origens místicas, mas se sustenta em explicações de ordem natural - determinadas pessoas possuem características e habilidade que são natas, em detrimento de outras que não possuem -, porém, se distingue das demais por não se sustentar sobre a coação.

A dominação de base legal, ancorada na racionalidade, é fundamentalmente desenvolvida nas modernas sociedades ocidentais e corresponde, em grande medida, ao desenvolvimento do capitalismo e a exigência da necessidade constante de racionalização dos processos, com vistas aos reflexos de otimização da produção e lucro. Os consequentes avanços das técnicas do processo de produção capitalista são incorporados pelo Estado, como, por exemplo, a contabilidade de custos e benefícios.

Neste processo, para Weber (2012), a racionalidade é compreendida como a melhor forma em que se articula meios e fins, não cabendo, todavia, a aplicação de valoração e julgamentos éticos e moral.

A partir dessas definições, Weber (2012) passa a interpretar e analisar o Estado como uma empresa de dominação racional, destacando duas necessidades básicas e inerentes a ele: o estado-maior administrativo e os meios materiais de gestão. De acordo com Lage (2013, p. 3 ), essas necessidades, respectivamente, significam "o conjunto de atividades organizadas voltadas a realização da obediência, e os recursos econômicos suficientes tanto para exercer a força física quanto para abrigar os funcionários”.

De acordo com Weber (2012), é preciso observar que a tendência centralizadora da gestão do Estado provocou a criação dos "Políticos Profissionais", o qual, ao acessar a instância estatal, tem o poder de decisão e mando, e que o histórico processo de encerramento das relações aristocráticas, tendo como consequência a não mais cessão de seus membros para trabalhar no Estado, exige do Estado financiar seu próprio corpo operador, seus funcionários que devem obedecer e executar as tarefas.

No que diz respeito à compreensão do político profissional em Weber, Lage (2013, p.4) apresenta as seguintes contribuições:

"É sobre essa forma de Estado, no contexto do ocidente, que viu-se surgir o "político profissional". Partindo de um critério econômico, o autor distingue aqueles que "vivem para a política", daqueles que "vivem da política". É evidente que a política, assim como definida, pode ser exercida por todos, mas há aqueles que a elegem como atividade principal e as que exercem ocasionalmente. Não obstante, o autor 
salienta que "todo homem sério, que vive para uma causa, vive também dela", mas isso não impede que a diferenciação econômica dos que "vivem para" e dos que "vivem da" política não seja relevante. Pelo contrário, defende Weber que na vida moderna nem o operário, tampouco o homem de negócios, o empresário, estão disponíveis suficientemente para a política. É oportuno, portanto, para a sobrevivência dos partidos políticos a disponibilização de pessoas que "vivam da" política e a tenham como profissão principal."

De outra forma, Weber ainda destaca que existem no moderno Estado democrático a estruturação de um aparelho burocrático tocado pelos funcionários de carreira, inamovíveis, vinculado e sujeito a uma hierarquia de comandos. A cadeia de comando se faz de forma tão bem articulada que tem como resultado a confusão dos funcionários em entender as ordens dos superiores como correspondente a suas próprias convicções (GODOY, 2012).

$\mathrm{Na}$ definição e atribuições dos comandos, para Weber (2012), se encontram os políticos profissionais, o qual dependem dos resultados da eleição para o seu ingresso e permanência no Estado, cuja honra se assenta na responsabilidade pessoal, diferentemente dos funcionários de carreira em que a honra está na obediência.

De acordo com Weber (2012), os políticos profissionais são movidos ou pela ética da convicção ou pela ética da responsabilidade, que são entendidas como posturas irredutivelmente opostas. Àquele que é movido pela ética da convicção, exemplificado como ética semelhante a proposta na religião cristã, pauta suas ações sob a observância de dogmas e crenças, visando o exercício de atitudes exemplares e coerente com os fins últimos.

Já o político profissional que é movido pela ética da responsabilidade, avalia constantemente suas ações sob um cálculo e medida do quanto de sucesso e positivo elas têm entre meios e fins propostos, por entender que será responsabilizado direta e pessoalmente pelos resultados atingidos.

Contudo, para Weber (2012) o político virtuoso transita e aplica com equilíbrio e satisfatoriamente os pressupostos das duas éticas em suas ações. A despeito da má impressão que a conciliação dessas duas éticas pode ensejar, observando que a política é o campo fundado na dominação e no poder, o autor alerta que:

\footnotetext{
“Quem deseje dedicar-se à política e, principalmente, quem deseje dedicar-se à política em termos de vocação deve tomar consciência desses paradoxos éticos e da responsabilidade quanto àquilo em que ele próprio poderá sobre pressão daqueles paradoxos. Repito que ele se compromete com potências diabólicas que atuam com toda a violência.” (WEBER, 2012, p. 120).
} 
A política, portanto, de um ponto de vista ético, está envolvida por dilemas e conflitos que são inevitáveis.

Weber (2012) ainda enfatiza que a ausência de um grande líder político tem como consequência negativa o império da burocracia e que, pelo contrário, é preciso fortalecer o constante controle sobre essa burocracia. Papel que cabe ao político profissional.

Por fim, conclui o autor: "A política é um esforço tenaz e enérgico para atravessar grossas vigas de madeira. Tal esforço exige, a um tempo, paixão e senso de proporções. É perfeitamente exato dizer que não se teria jamais atingido o possível, se não se houvesse tentado o impossível." (WEBER, 2012, p. 123).

\section{ELLEN WOOD E A CONSTATAÇÃO DO ESVAZIAMENTO DO POVO NA MODERNA DEMOCRACIA}

Wood (2015), no capítulo "O Demos Versus "Nós, o Povo": das Antigas às Modernas Concepções de Cidadania", do livro "Democracia Contra Capitalismo: a renovação do materialismo histórico", trabalha com a contraposição dos valores de cidadania relacionados a forma do exercício da democracia na antiga Atenas e nas modernas sociedades ocidentais.

\footnotetext{
"Se a cidadania é um conceito constitutivo da democracia antiga, o princípio fundamental da outra variedade [democracia moderna] é, talvez, o senhorio. O cidadão ateniense afirmava não ter senhor, não ser servo de nenhum homem mortal. Não era devedor de serviço nem de deferência a nenhum senhor, nem se preocupava com a obrigação de enriquecer com seu trabalho algum tirano. A liberdade que sua cidadania tornava possível era a liberdade do demos em relação ao senhorio. A Magna Carta, ao contrário, não foi um documento de um demos livre, mas dos próprios senhores que afirmaram privilégios feudais e a liberdade da aristocracia tanto contra a Coroa quanto a multidão popular, assim como a liberdade de 1688 representou o privilégio dos senhores proprietários de dispor como quisessem de sua propriedade e de seus servos." (WOOD, 2015, p. 177).
}

Assim, a democracia ateniense é entendida como promotora da quebra da ancestral oposição existente entre governantes e produtores, transformando camponeses em cidadãos. Contudo, nas sociedades camponesas da Europa moderna tem-se a divisão entre governantes e súditos camponeses como condição constitutiva da "soberania popular" (WOOD, 2015, p. 178).

A autora, sobre o referido afastamento entre governantes e súditos nas sociedades moderna, com prejuízos negativos sobre a cidadania deste último, e as consequências para o 
regime democrático representativo, apresenta que ganha corpo uma doutrina da supremacia parlamentar que tem como função atuar contra o poder popular.

Exemplificando a sua afirmação, Wood (2015) apresenta que na Inglaterra de hoje, como consequência desse processo, é fácil perceber que a produção da política reconhecida como legítima se dá apenas no parlamento.

\begin{abstract}
"O Parlamento é o responsável último perante seu eleitorado, mas o "povo" não é realmente soberano. Para todos os efeitos, não existe política - pelo menos política legítima - fora do Parlamento. De fato, quanto mais inclusivo se torna o termo "povo", mais as ideologias políticas dominantes - dos conservadores à corrente principal do trabalhismo - insistiam na despolitização do mundo fora do Parlamento e na deslegitimação da política "extraparlamentar". Paralelamente a esse processo, ocorreu uma centralização crescente do poder parlamentar no executivo, produzindo algo semelhante à soberanização do gabinete, ou até mesmo do próprio cargo de primeiro-ministro." (WOOD, 2015, p. 178-179).
\end{abstract}

Nesse processo, de acordo com Wood (2015) é preciso compreender que o capitalismo deslocou o centro do poder para a propriedade, deixando de ser o senhorio, como no passado. Ao realizar esse movimento o sistema capitalista torna menos importante o estado cívico e os privilégios políticos se sucumbem às vantagens econômicas, promovendo o surgimento de uma nova forma de democracia.

Ainda, em relação as contraposições entre a democracia ateniense e das modernas sociedades capitalistas, Wood (2015) pontua que na primeira encontramos uma cidadania envolvia em um processo no qual os camponeses estavam livres da exploração extraeconômica e sua participação política limitava a exploração política, não estando sujeitos ainda às pressões econômicas de propriedade. Neste sentido, a participação do homem comum na política permitia inclusive contribuir com mudanças substanciais nas desigualdades socioeconômicas, fato o qual permite afirmar que, de certa forma, a democracia ateniense não se limitava aos aspectos formal, mas se estendia para a vida concreta.

Em contraponto, na democracia capitalista, temos:

“[...] a separação entre a condição cívica e a posição de classe opera nas duas direções: a posição socioeconômica não determina o direito à cidadania - e é isso o democrático na democracia capitalista -, mas, como o poder do capitalista de apropriar-se do trabalho excedente dos trabalhadores não depende de condição jurídica ou civil privilegiada, a igualdade civil não afeta diretamente nem modifica significativamente a desigualdade de classe - e é isso que limita a democracia no capitalismo. As relações de classe entre capital e trabalho podem sobreviver até mesmo à igualdade jurídica e ao sufrágio universal. Neste sentido, a igualdade política na democracia capitalista não somente coexiste com a desigualdade socioeconômica, mas deixa fundamentalmente intacta." (WOOD, 2015, 184). 
$\mathrm{Na}$ base desse complexo processo de cisão entre condição cívica e posição de classe das sociedades capitalistas, que reflete na vivência de uma igualdade política, mas essencialmente superficial já que coexistindo com as desigualdades socioeconômicas, sem nada contribuir para o seu enfrentamento, destaca-se o movimento federalista. Pois, de acordo com Wood (2015) foram justamente os antidemocratas vitoriosos nos Estados Unidos, no movimento federalista, que apresentaram ao mundo moderno a definição de democracia em que em essência o poder popular está diluído.

A autora coloca em questão as premissas sobre as quais se sustentou a concepção federalista de democracia, movendo a democracia direta para a representativa, indireta. Para Wood (2015), a representação não era concebida apenas como uma forma de distanciar o povo da política, mas também por favorecer as classes proprietárias. Assim, ela afirma que: “A "democracia representativa", tal como uma das misturas de Aristóteles, é a democracia civilizada com o toque de oligarquia." (WOOD, 2015, p. 188).

Articulado e decorrente desse quadro, adentra em questão os valores liberais com influência direta sobre a democracia, colocando em conflito a sua razão de existir.

\footnotetext{
"Num tempo de mobilização de massa, o conceito de democracia foi submetido a novas pressões ideológicas pelas classes dominantes, exigindo não somente a alienação do poder "democrático" mas a separação clara entre a "democracia" e o "demos" - ou, no mínimo, o afastamento decidido do poder popular como principal critério de valor democrático. O efeito foi a mudança de foco da "democracia", que passou do exercício ativo do poder popular para o gozo passivo das salvaguardas e dos direitos constitucionais e processuais, e do poder coletivo das classes subordinadas para a privacidade e o isolamento do cidadão individual. Mais e mais, o conceito de "democracia" passou a ser identificado como liberalismo." (WOOD, 2015, p. 196).
}

Assim, temos que o liberalismo coloca em cena valores centrais que são diametralmente opostos aos democráticos, como o individualismo em detrimento do coletivo, defesa dos bens patrimoniais em detrimento dos bens públicos e a defesa de um Estado limitado em suas funções sociais. Desta forma, Wood (2015) afirma que o liberalismo se apresenta como um conjunto de ideias e instituições com claras intenções de limitar o poder do Estado, mas com valores que se apresentam como substitutos a própria democracia.

Nesta esteira, a autora afirma que o capitalismo possibilitou a redefinição da democracia, em um primeiro momento, e a sua própria redução ao liberalismo, em um segundo momento. As consequências desse processo se reflete negativamente na medida em que: 
"A democracia liberal deixa intocada toda a nova esfera de dominação e coação criada pelo capitalismo, sua transferência de poderes substancias do Estado para a sociedade civil, para a propriedade privada e as pressões do mercado. Deixa intocadas vastas áreas de nossa vida cotidiana - no local de trabalho, na distribuição do trabalho e dos recursos - que não estão sujeitos à responsabilidade democrática, mas são governadas pelos poderes da propriedade, pelas "leis" do mercado e pelo imperativo do lucro.” (WOOD, 2015, p. 201)

Apesar dos efeitos devastadores que o capitalismo e sua vertente liberal vem provocando à democracia, Wood (2015) destaca que é preciso observar que a democracia moderna também apresenta ganhos, pois tornou-se mais inclusiva, finalmente aboliu a escravidão e permitiu a cidadania as mulheres e aos trabalhadores. Além disso, ressalta que há ganhos com a promoção do respeito às liberdades civis e dos direitos humanos. Contudo, é inegável as contradições desse processo de modo que à medida que os direitos políticos se tornaram menos exclusivos também perderam muito de seu poder transformador.

Por fim, Wood (2015) enfatiza que “enquanto houver Estado, haverá a necessidade de controlar seu poder e proteger os poderes e as organizações independentes que existem fora do Estado" e desta forma, como expressão de um poder social, precisa estar envolto pela proteção das liberdades - associação, comunicação, diversidade de opiniões, de uma esfera privada inviolável etc. Todavia, para a autora o liberalismo, enquanto ideal e ação, não possui os valores e conteúdos capaz de abranger uma democracia mais inclusiva.

\section{CONSIDERAÇÕES FINAIS}

Conforme destacado no início deste trabalho, as definições atribuídas aos temas proposto pelos autores, devem ser observados à luz da compreensão dos diferentes períodos históricos e experiências vividas por cada um, sopesando as posições de classes ocupadas e diferentes trajetórias seguidas. Considerando esse processo, é certo que tenham olhares e objetivos diferenciados, ainda que, em determinado momento, se utilizem e versem sobre uma mesma temática.

Podemos perceber que há entre os autores uma maior ou menor distinção entre as concepções de Política e Estado, sendo que a análise da democracia enquanto sistema de organização e distribuição do poder é realizada objetivamente apenas por Ellen Wood.

Neste sentido, podemos perceber que enquanto a política para Maquiavel deve ser vista e, por consequência, analisada separada de valores ético e moral, sendo possuidora de 
leis próprias, para Weber ela também deve ser entendida sob normas específicas, mas compreendendo que possui regras e éticas que são próprias da política, além disso, a sua realização deve estar atrelada a uma vertente estatal.

Diferentemente, Wood apresenta no bojo da ação política o exercício da democracia. Cabe a ela promover a cidadania, integrando e valorizando a participação do povo nos espaços de poder. Todavia, a democracia representativa no sistema capitalista liberal tem servido para a intensificação do afastamento entre representantes e representados e, permeado o desatendimento das necessidades econômicas, política, social e cultural da população, ruindo com a realização da cidadania.

$\mathrm{Na}$ outra ponta, Maquiavel defende que a política tem duas finalidades, "a manutenção da ordem pública nas relações internas; e a defesa da integridade da pátria nas relações externas", e Weber que a política é "a direção do agrupamento político hoje denominado "Estado" ou a influência que se exerce em tal sentido".

No que diz respeito às definições de Estado, Wood trabalha com a concepção de Estado enquanto aparelho e instrumento de dominação de uma classe sobre a outra, defendendo que enquanto ele existir haverá a necessidade de disputar e controlar o seu poder.

Weber, de outra forma, enfatiza e denomina o Estado enquanto detentor do monopólio do uso legítimo da força física, como condição de imposição da ordem e reprodução social. Um Estado que também deve ser entendido como um espaço de concretização de relação de dominação do homem sobre o homem e que só existe pelo reconhecimento e submissão dos homens dominados à autoridade dos que se reivindicam e exercem a dominação.

Já para Maquiavel, o Estado é visto como o detentor do poder central, o qual compete ordenar sobre a vida da população, de modo a organizar e encaminhar interesses conflitantes seja por via da sua canalização ou regulamentação. Para tanto, a sua atuação deve se basear na força, mediante a criação de instituições intervencionistas, como o exército, leis, normas etc. Cabe ao Príncipe, dentro das condições dadas, lidar da melhor forma possível com a realização das finalidades do Estado e da política.

Neste contexto, é certo que as análises e definições atribuídas aos temas em estudo, pelos autores, não dão conta e acompanham toda a complexidade que abrangem o desenvolvimento histórico e social. Todavia, a grandeza das definições produzidas é que muito de sua essência, com maior ou menor intensidade, ainda estão presentes e nos ajudam a compreender fatos e fenômenos que hoje se encontram envoltos e acometem a política, o Estado e a democracia, possibilitando entender de forma mais clara as intenções e motivações 
que estão por trás de muitas ações, bem como mensurar pontos positivos e negativos dos impactos esperados e mesmo desdobramentos e consequências advindas.

\section{BIBLIOGRAFIA}

CARLI, Maria V. Inocêncio. Resumo analítico da obra O Príncipe. Revista Agusvinnus, Buenos Aires, $\mathrm{n}^{\circ} 1-$ ENERO 2015, pp. 207-215. Disponível em: agusvinnus.prodiversitas.org/revistas/Carli-1.pdf. Acesso em: 24 jul. 2017.

KRITSCH, Raquel. Maquiavel e a Construção da Política. Lua Nova [online]. 2001, n.53, pp.181-190. Disponível em: http://www.scielo.br/scielo.php?pid=S010264452001000200009\&script=sci_abstract\&tlng=pt. Acesso em: 20 jul. 2017.

MACHIAVELli, Niccollò. O Príncipe. Escrito Políticos. Tradução de Lívio Xavier. São Paulo: Circulo do Livro, 1996.

GODOY, Arnaldo S. de Morais. A política como Vocação, de acordo com Max Weber. Boletim de Notícias CONJUR [online]. 2012, Colunistas pp. 1-3. Disponível em: http://www.conjur.com.br/2012-set-16/embargos-culturais-politica-vocacao-acordo-maxweber. Acesso em: 18 jul. 2017.

LAGE, Daniel. Reflexões sobre a leitura de "A Política como Vocação" de Max Weber. Resenhas críticas [online]. 2013, pp. 1-9. Disponível em: https://lage.milharal.org/2013/05/24/reflexoes-sobre-a-leitura-de-a-politica-como-vocacao-demax-weber/ . Acesso em: 19 jul. 2017.

WEBER, Max. Ciência e Política: duas vocações. Tradução de Leonidas Hegenberg e Octany Silveira da Mota. São Paulo: Cultrix, 18 a ed. 2012.

WOOD, Ellen Meiksins. Democracia Contra Capitalismo: a renovação do materialismo histórico. Tradução de Paulo Cezar Castanheira. São Paulo: Boitempo, 2011. 